\title{
ESTABILIDADE DA PRODUÇÃO DE GERMOPLASMA DE MILHO AVALIADO EM DIFERENTES REGIÕES DO BRASIL'
}

\author{
ELTO EUGENIO GOMES E GAMA², SIDNEY NETTO PARENTONI ${ }^{3}$, CLESO ANTÔNIO PATTO PACHECO ${ }^{4}$, \\ ANTÔNIO CARLOS DE OLIVEIRA ${ }^{4}$, PAULO EVARISTO DE OLIVEIRA GUIMARÃES ${ }^{3}$ e MANOEL XAVIER DOS SANTOS ${ }^{4}$
}

\begin{abstract}
RESUMO - Este trabalho teve por objetivo obter informações quanto aos aspectos relacionados aos padrões de respostas apresentados por 30 diferentes genótipos de milho (híbridos, cultivares e populações), avaliados em 14 diferentes ambientes do Brasil, no ano agrícola de 1995/96. Foram obtidas as estimativas dos parâmetros de estabilidade da produção de espigas despalhadas. Os genótipos estudados apresentaram comportamento diferenciado quanto à adaptabilidade da produção. Os híbridos foram mais adaptados que as cultivares e populações. O híbrido triplo P 3041 foi o mais produtivo, porém de baixa previsibilidade e estabilidade nos ambientes estudados. As cultivares CMS 50 e BR 106 apresentaram a primeira e a quinta melhores produções, respectivamente, entre as cultivares estudadas, porém não foram muito resistentes ao baixo nível tecnológico. Foi possível identificar genótipos promissores para utilização de imediato e em programas de melhoramento.
\end{abstract}

Termos para indexação: Zea mays, interação genótipo-ambiente, fatores ambientais, população de plantas, cultivares, híbridos, adaptação.

\section{YIELD STABILITY OF MAIZE GERMOPLASM EVALUATED IN SEVERAL REGIONS OF BRAZIL}

\begin{abstract}
The objective of this work was the obtention of information on the response pattern of 30 maize genotypes in 14 environments of Brazil in 1995/96. The stability parameters of ear yield were estimated. All the genotypes varied for yield adaptability. The three-way cross P 3041 presented the best yield and showed low stability to a deterioration on environmental variations. The open pollinated materials CMS 50 and BR 106 were, respectively, the first and fifth best yieldings among all the studied maize genotypes, with low adaptation on unfavorable environments. The identification of promising maize genotype was possible for immediate utilization and as a source of germplasm in breeding programs
\end{abstract}

Index terms: Zea mays, genotype environment interaction, environmental factors, cultivars, plant population, hybrids, adaptation.

\section{INTRODUÇÃO}

Os trabalhos de melhoramento de milho tiveram início no Brasil na década de 30, com o desenvolvimento de programas para a produção de cultivares e híbridos a partir de populações tropicais, de ciclo

\footnotetext{
${ }^{1}$ Aceito para publicação em 9 de julho de 1999.

${ }^{2}$ Eng. Agrôn., Ph.D., Embrapa-Centro Nacional de Pesquisa de Milho e Sorgo (CNPMS), Rodovia MG 424, $\mathrm{km} 65$ Caixa Postal 151, CEP 35701-970 Sete Lagoas, MG. E-mail: gamaelto@cnpms.embrapa.br

${ }^{3}$ Eng. Agrôn., M.Sc., Embrapa-CNPMS

${ }^{4}$ Eng. Agrôn., Dr., Embrapa-CNPMS.
}

tardio e porte alto da planta (Krug et al., 1943). Os programas de melhoramento permitiram que fossem alcançados sucessos substanciais com a obtenção de cultivares melhoradas e híbridos superiores às cultivares existentes e comercializadas no País (Paterniani \& Miranda Filho, 1978).

Com a evolução da agricultura e o direcionamento para atender também as peculiaridades das diferentes regiões produtoras desse cereal, os melhoristas se vêem empenhados em trabalhar com populações que por seleção possam fornecer cultivares com tipos de plantas de menor porte, mais precoces, eficientes e mais produtivas. Atualmente, a contribuição 
de germoplasma de milho tropical com ou sem introgressão de genes de milhos temperados tem sido notória para o aumento da área plantada, bem como para incrementar a aceitação dessas cultivares de ciclo precoces ou semiprecoces para plantio no País.

A importância de germoplasma de base ampla no melhoramento de milho é enfatizada por Sprague (1955), Lonnquist (1967) e Hallauer \& Miranda Filho (1981).

Na literatura brasileira, inexistem referências a estudos sobre o comportamento de populações de milho de ciclo precoce e com características agronômicas modernas, quanto à estabilidade de produção em comparação com híbridos comerciais, que possam ser utilizadas em programas de melhoramento. Essas informações são de grande interesse, uma vez que fornecem aos melhoristas uma indicação do padrão de resposta de cada cultivar às variações ambientais.

Vários métodos têm sido utilizados para obtenção de estimativas de parâmetros de adaptabilidade e estabilidade. Finlay \& Wilkinson (1963), Eberhart \& Russell (1966) e Lin \& Binns (1988) empregaram métodos baseados no coeficiente de regressão linear e na variância dos desvios da regressão estimados em relação a cada cultivar (Arias et al., 1996). A regressão relaciona as médias da cultivar nos diferentes ambientes, com os chamados índices ambientais, definidos como desvios entre as médias de ambientes e a média geral. Lin et al. (1986), Becker
\& León (1988) e Crossa (1990) enfatizaram que este método apresenta certas limitações, como o uso da média de todas as cultivares em cada ambiente como índice ambiental, e que sob tal procedimento pode não ocorrer a independência entre as variáveis, principalmente sendo o número de cultivares inferior a 15. Verma et al. (1978) e Cruz et al. (1989) utilizaram um modelo de regressão composto de dois segmentos de reta, a regressão bilinear.

O objetivo deste trabalho foi estudar a adaptação de diferentes populações e cultivares de milho de ciclo precoce, em locais de diferentes regiões do País, tendo como testemunha alguns híbridos comerciais.

\section{MATERIAL E MÉTODOS}

Estudou-se o comportamento de cultivares e populações de milho de polinização livre, plantadas em algumas das principais regiões produtoras (Sul, Centro-Sul e Centro-Oeste) do País. Foram obtidas de pesquisadores de diferentes instituições de pesquisa governamentais que trabalham com a cultura do milho amostras de sementes de germoplasma mais em uso nas suas regiões. No ano agrícola 1995/96, os ensaios foram devidamente preparados e remetidos aos colaboradores.

Os experimentos foram conduzidos no ano agrícola de 1995/96, em 16 diferentes ambientes do País. As produções médias dos ensaios, as coordenadas geográficas (latitude e longitude), altitudes, e as precipitações pluviais médias dos locais estudados são apresentadas na Tabela 1 .

TABELA1. Tipo de solo, produção média dos ensaios (kg/ha), coordenadas geográficas, altitude e precipitação pluvial anual dos locais onde foram conduzidos os ensaios para avaliação de 30 genótipos de milho, em 1995. Sete Lagoas, MG, 1996.

\begin{tabular}{|c|c|c|c|c|c|c|}
\hline Local & Tipo de Solo & $\begin{array}{l}\text { Produção média } \\
\text { do ensaio (kg/ha) }\end{array}$ & Latitude & Longitude & $\begin{array}{l}\text { Altitude } \\
\text { (m) }\end{array}$ & $\begin{array}{c}\text { Precipitação pluvial } \\
(\mathrm{mm})\end{array}$ \\
\hline Campos dos Goytacazes (RJ) & Latossolo Amarelo distrófico & 6190 & $21^{\circ} 45^{\prime}$ & $41^{\circ} 19^{\prime}$ & 13 & 1305 \\
\hline Palotina (PR) & Latossolo Roxo distrófico & 4930 & $24^{\circ} 17^{\prime}$ & $53^{\circ} 30^{\prime}$ & 333 & 1350 \\
\hline Londrina (PR) & Terra Roxa Estruturada & 5560 & $23^{\circ} 23^{\prime}$ & $51^{\circ} 11^{\prime}$ & 566 & 1622 \\
\hline Ponta Grossa (PR) & Podzólico Vermelho-Amarelo & 7240 & $25^{\circ} 05^{\prime}$ & $50^{\circ} 9^{\prime}$ & 969 & 1613 \\
\hline Chapecó (SC) & Terra Roxa Estruturada & 6670 & $20^{\circ} 07^{\prime}$ & $52^{\circ} 37^{\prime}$ & 668 & 1954 \\
\hline Sidrolândia (MS) & Latossolo Verm.-Escuro & 5360 & $20^{\circ} 56^{\prime}$ & $54^{\circ} 57^{\prime}$ & 484 & 1474 \\
\hline Campo Grande (MT) & Latossolo Verm.-Amarelo & 3840 & $20^{\circ} 27^{\prime}$ & $54^{\circ} 37^{\prime}$ & 530 & 1469 \\
\hline Goiânia (GO) & Latossolo Verm.-Amarelo & 7110 & $16^{\circ} 40^{\prime}$ & $49^{\circ} 15^{\prime}$ & 741 & 1576 \\
\hline Goianésia (GO) & Podzólico Verm.-Amarelo & 3989 & $15^{\circ} 19^{\prime}$ & $49^{\circ} 7^{\prime}$ & 650 & 1575 \\
\hline Campinas (SP) & Latossolo Roxo eutrófico & 5700 & $22^{\circ} 54^{\prime}$ & $47^{\circ} 3^{\prime}$ & 854 & 1625 \\
\hline Pelotas (RS) & Planossolo distrófico & 3760 & $31^{\circ} 46^{\prime}$ & $52^{\circ} 20^{\prime}$ & 17 & 1405 \\
\hline Sete Lagoas (MG) & Latossolo Verm.-Esc. distr. & 7060 & $19^{\circ} 28^{\prime}$ & $44^{\circ} 15^{\prime}$ & 732 & 1328 \\
\hline Coimbra (MG) & Podzólico Verm.-Amar. distr. & 3780 & $20^{\circ} 51^{\prime}$ & $42^{\circ} 48^{\prime}$ & 720 & 1220 \\
\hline Janaúba (MG) & Latossolo Verm.-Amar. dist. & 6130 & $15^{\circ} 48^{\prime}$ & $43^{\circ} 18^{\prime}$ & 533 & 830 \\
\hline
\end{tabular}


Foram avaliados 30 genótipos de milho abrangendo cinco híbridos comerciais e 25 populações de polinização livre (Tabela 2).
O delineamento experimental adotado em todos os ensaios foi o de látice $5 \times 6$, com três repetições. A parcela foi constituída por uma fileira de $5 \mathrm{~m}$, e o espaçamento médio

TABELA 2. Médias de produção de espigas de 14 locais $^{1}$ do Brasil (kg/ha)e estimativas de parâmetros de estabilidade $^{2}$ obtido pelo método de Cruz et al. (1989). Sete Lagoas, MG, $1996^{3}$.

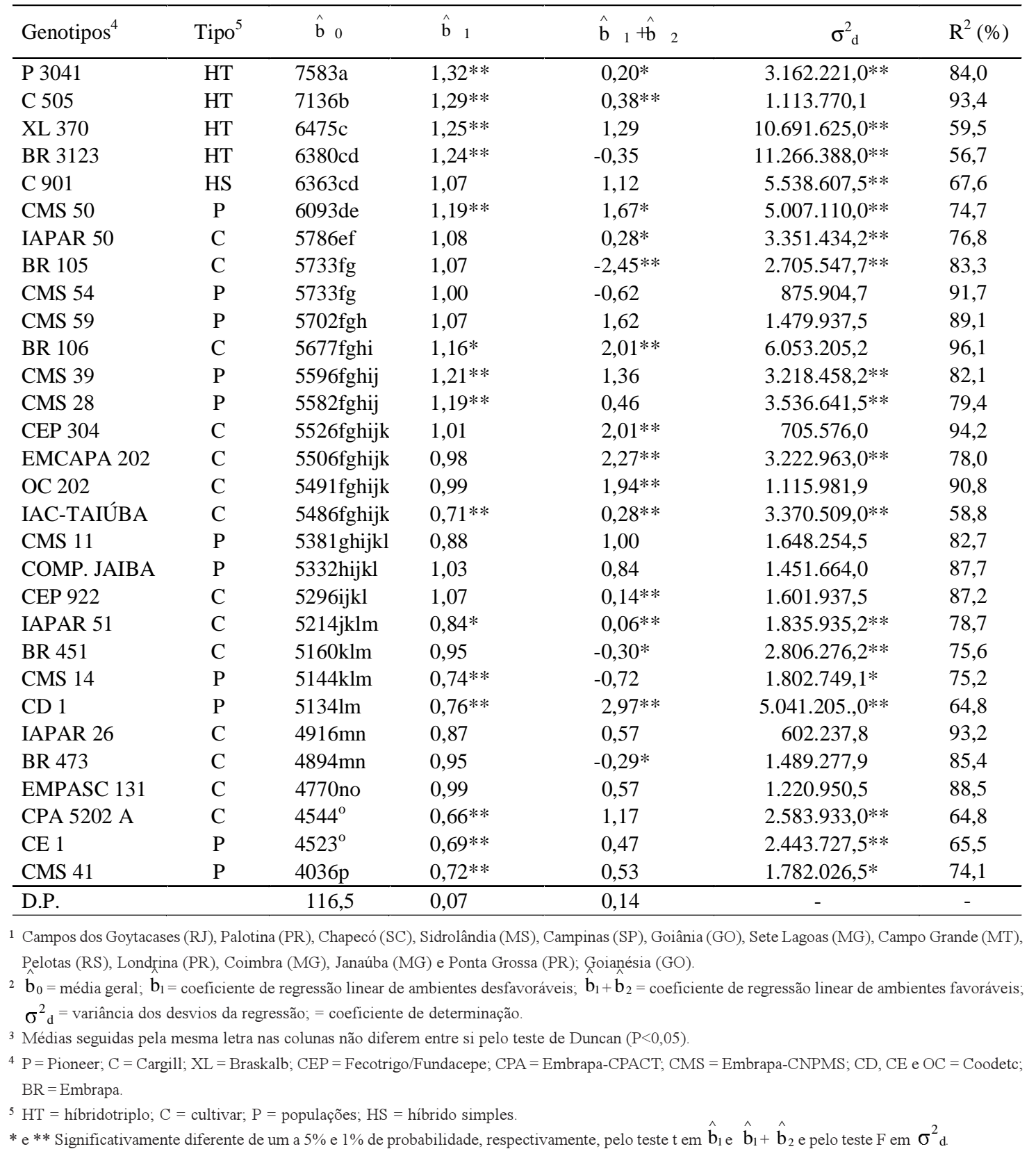


adotado foi de $0,90 \mathrm{~m}$ entre fileiras e $0,20 \mathrm{~m}$ entre plantas na fileira. As adubações foram efetuadas de acordo com as análises dos solos e as necessidades da cultura. Os tratos culturais foram efetuados quando necessário.

$\mathrm{Na}$ avaliação do caráter produção de espigas despalhadas, corrigida para $14,5 \%$ de umidade, primeiramente foi feito um estudo da relação entre os quadrados médios dos resultados das análises de variância individuais dos 16 ambientes, e verificou-se que somente 14 deles poderiam ser reunidos numa análise de variância conjunta (Pimentel-Gomes, 1990). Os parâmetros de adaptabilidade foram estimados pelo método modificado por Cruz et al. (1989) onde a correlação entre as estimativas $\mathrm{b}_{1} \mathrm{e}\left(\mathrm{b}_{1}+\mathrm{b}_{2}\right)$ é nula (Vencovsky \& Barriga, 1992).

\section{RESULTADOS E DISCUSSÃO}

A Tabela 3 resume a análise de variância conjunta simplificada, referente ao caráter peso de espigas despalhadas, com os respectivos níveis de significância e o coeficiente de variação. Verificam-se diferenças altamente significativas $(\mathrm{p}<0,01)$ quanto a locais, genótipos, e interação locais $x$ genótipo $(\mathrm{L} \times \mathrm{G})$. A significância da interação $\mathrm{L} x \mathrm{G}$ sugere a existência de um comportamento linear diferenciado dos genótipos em face dos diferentes ambientes, permitindo-se, assim, o estudo pela análise de estabilidade proposta.

As médias de produção dos ensaios variaram de $3.760 \mathrm{~kg} / \mathrm{ha}$ (Pelotas, RS) a $7.240 \mathrm{~kg} / \mathrm{ha}$ (Ponta Grossa, PR), indicando a existência de uma ampla faixa de

TABELA 3. Análise de variância conjunta simplificada, referente ao caráter peso de espigas despalhadas (kg/ha), de 30 genótipos de milho avaliados em 14 ambientes no Brasil. Sete Lagoas, MG, 1996.

\begin{tabular}{llc}
\hline Fonte de variação & \multicolumn{1}{c}{ G.L. } & QM \\
\hline Locais (L) & 13 & $253.112 .064,0^{* * *}$ \\
Genótipos (G) & 29 & $22.970 .710,0^{* * *}$ \\
L x G & 377 & $3.088 .730,25^{* *}$ \\
Resíduo & 688 & $570.067,0$ \\
\hline Média (kg/ha) & 5.540 & \\
\hline CV $(\%)$ & 13,63 & \\
** Significativo a 1\% de probabilidade pelo teste de F.
\end{tabular}

** Significativo a $1 \%$ de probabilidade pelo teste de $\mathrm{F}$

Pesq. agropec. bras., Brasília, v.35, n.6, p.1143-1149, jun. 2000 variação ambiental onde os genótipos foram avaliados. Parte dessas variaçõos ocorreram provavelmente em função das diferenças de solo. Em solos de Cerrado foram registradas as menores produtividades $\mathrm{e}$ em terras roxas os genótipos de milho expressaram melhor os seus potenciais produtivos. Os valores dos coeficientes de variação obtidos nas análises de variância individuais variaram de $8,71 \%$ (Palotina, $\mathrm{PR}$ ) a 18,79\% (Goiânia, GO), indicando, em média, uma precisão razoável dos ensaios. As produtividades médias de espigas $\left(\hat{b}_{0}\right)$, os coeficientes de regressão lineares $\left(\hat{b}_{1} \mathrm{e} \hat{b}_{2}\right)$, as variâncias dos desvios da regressão $\left(\sigma^{2}\right)$ e os coeficientes de determinação $\left(R^{2}\right)$ de cada genótipo, nos 14 ambientes estudados, encontram-se na Tabela 2. As produtividades médias de espigas variam de $4.036 \mathrm{~kg} / \mathrm{ha} \mathrm{a} 7.583 \mathrm{~kg} / \mathrm{ha}$, respectivamente para a população CMS 41 e o híbrido triplo P 3041, e a média geral dos ensaios foi de $5.540 \mathrm{~kg} / \mathrm{ha}$. Quanto ao coeficiente de regressão $\left(\hat{b}_{1}\right)$, que corresponde à resposta linear do genótipo a variações nos ambientes desfavoráveis, as estimativas variaram de 0,66 a 1,32, respectivamente, em relação aos genótipos CPA 5202 A e P 3041, sendo ambos significativamente diferentes da unidade $(\mathrm{P}<0,01)$. Dos 30 genótipos, somente 15 apresentaram valores de $\hat{b}_{1}$ significativamente diferentes da unidade, e 15 apresentaram $\hat{b}_{1}$ não-significativos ( $\hat{b}_{1}=1$ ), evidenciando o comportamento diferenciado desses genótipos em ambientes desfavoráveis. Os híbridos P 3041, C 505 e BR 3123 mostram-se muito exigentes nos ambientes desfavoráveis $\left(\hat{b}_{1}>1\right)$. Com relação à resposta nos ambientes favoráveis, esses três híbridos não responderam à aplicação de insumos, ou seja, não apresentaram resposta à melhoria do ambiente $\left(\hat{b}_{1}+\hat{b}_{2}<1\right)$. A estimativa de $\mathrm{R}^{2}>90 \%$ para 0 C 505 indicou um bom ajustamento às retas de regressão, o que implica em boa previsibilidade de resposta. Esses dois primeiros híbridos apresentaram as maiores produtividades, sendo $22,38 \%$ e $26,95 \%$, respectivamente, superiores à média dos ensaios.

As populações CMS 28 e CMS 39 e o híbrido XL 370 mostraram ser exigentes mesmo nos ambientes desfavoráveis $\left(\hat{b}_{1}>1\right)$, mas com resposta proporcional a mudanças de ambientes $\left(\hat{b}_{1}+\hat{b}_{2}=1\right)$, em ambientes mais favoráveis. Quanto às estimativas de $\mathrm{R}^{2}$, ficou evidenciado que esses genótipos apresentaram baixa previsibilidade ou instabilidade de comportamento. O híbrido XL 370, o terceiro mais produ- 
tivo, foi $13,79 \%$ mais produtivo que a população CMS 28 (5.582 kg/ha).

Os genótipos IAC-Taiúba, IAPAR 51 e CMS 14 apresentaram maior adaptação para ambientes desfavoráveis $\left(\hat{b}_{1}<1\right)$, mas não foram tão respon$\operatorname{sivos}\left(\left(\hat{b}_{1}+\hat{b}_{2}\right)<1\right]$ para melhoria das condições ambientais. Na média, a cultivar IAC-Taiúba $(5.486 \mathrm{~kg} / \mathrm{ha})$ produziu um pouco mais que o IAPAR 51 (5.214 kg/ha), ambos com produtividades pouco abaixo da média dos ensáios. A variância do desvio da regressão $\left(\sigma_{\mathrm{d}}^{2}\right)$ e o coeficiente de determinação $\left(\mathrm{R}^{2}\right)$, segundo Pinthus (1973), são parâmetros que fornecem as mesmas informações. Com base nas estimativas desses parâmetros, pode-se inferir que o comportamento desses dois genótipos será errático ou imprevisível.

O Composto Duro 1 também apresentou maior adaptação para ambientes desfavoráveis $\left(\hat{b}_{1}<1\right)$; foi responsivo a ambientes favoráveis ou superiores $\left.\mid\left(\hat{b}_{1}+\hat{b}_{2}\right)>1\right]$. Este seria o tipo ideal de genótipo, pois se apresentou resistente a uma deterioração da qualidade ambiental e responsivo em condições ambientais favoráveis; no entanto, foi pouco produtivo, ou seja, 7,31\% menos produtivo que a média geral dos ensaios.

Os genótipos BR 473, BR 451 e CEP 922 (com produtividade abaixo da média), IAPAR 50, BR 105 e CMS 54 (com produtividade acima da média), apresentaram decréscimo de rendimento, dentro do esperado, à medida que o ambiente piorou $\left(\hat{b}_{1}=1\right)$. Suas produtividades, em torno da média do ensaio, variaram de 4.894 (BR 473) a $5.786 \mathrm{~kg} / \mathrm{ha}$ (IAPAR 50). Estes materiais não mostraram ser responsivos com a melhoria das condições do ambiente $\left[\left(\hat{b}_{1}+\hat{b}_{2}\right)<1\right]$. Os genótipos EMCAPA 202, OC 202 e CEP 304 apresentaram adaptabilidade ampla nos ambientes desfavoráveis $\left(\hat{b}_{1}=1\right)$ e foram responsivos com a melhoria das condições ambientais $\left[\left(\hat{b}_{1}+\hat{b}_{2}\right)>1\right]$, o que concorda com os resultados obtidos por Arias (1996) em relação ao genótipo OC 202. Entre eles, o genótipo CEP 304 foi o que apresentou o mais baixo valor de $\sigma_{\mathrm{d}}^{2}$, o que significa um comportamento altamente previsível; o $\mathrm{R}^{2}>90 \%$ indica um adequado ajustamento dos dados à reta da regressão.
A cultivar BR 106 e a população CMS 50 apresentaram-se como exigentes em ambientes desfavoráveis, não resistindo a baixos níveis tecnológicos, mas foram responsivas à melhoria de ambientes. $\mathrm{O}$ melhoramento genético tem direcionado a cultivar BR 106 para plantios com um certo nível de tecnologia, pois este estudo indicou que ela apresentou pouca adaptação a ambiente desfavorável mostrado pelo $\left(\hat{b}_{1}>1\right)$ significativo a 5\%; apesar de um comportamento instável, apresentou $\mathrm{R}^{2}=96,1 \%$, indicando um bom ajuste da sua variabilidade em função dos índices ambientais ao modelo linear proposto. Entretanto, para a CMS 50 observou-se, quanto aos parâmetros $\sigma_{\mathrm{d}}^{2} \mathrm{e} \mathrm{R}^{2}$, uma indicação de comportamento instável. A cultivar BR 106, de polinização livre, atualmente é a mais plantada no País. Estima-se que entre $20 \%$ a $25 \%$ da área plantada com sementes melhoradas de milho no Brasil tem utilizado a cultivar BR 106. Essa cultivar apresentou uma produtividade média similar à da cultivar BR 105, de grãos duros, lançada pelo sistema Embrapa no mesmo ano (1987) que a BR 106

Fazendo uma comparação entre materiais de bases ampla e estreita, foram identificados alguns genótipos (IAPAR 50, BR 105, CMS 54, CMS 59 e BR 106) promissores para utilização de per si ou em programas de melhoramento que apresentaram boas produtividades mesmo sendo inferiores $(23,68 \%$, em média) à do híbrido mais produtivo (P 3041).

Os genótipos C 901, CMS 59, CMS 11, IAPAR 26, EMPASC 131 e o Composto Jaíba apresentaram adaptabilidade ampla nos ambientes desfavoráveis $\left(\hat{\mathrm{b}}_{1}=1\right)$, e também nos ambientes favoráveis $\left(\hat{\mathrm{b}}_{1}+\hat{\mathrm{b}}_{2}=1\right)$. Em termos de previsibilidade de comportamento, os mais e menos estáveis foram, respectivamente, os genótipos C $901\left(\mathrm{R}^{2}=67,6 \%\right)$ e IAPAR $26\left(\mathrm{R}^{2}=93,2 \%\right)$. Os mais produtivos foram o híbrido C 901 e a população CMS 59, sendo $12,95 \%$ e $2,92 \%$, respectivamente, superiores à média dos ensaios. Dos cinco híbridos comerciais estudados, somente o C 901 apresentou adaptabilidade ampla. Verifica-se, portanto, que um híbrido simples apresentou maior estabilidade que os híbridos triplos e duplos, de bases mais amplas, o que concorda com os resultados apresentados por Hallauer (1967), Naspolini Filho (1975) e Russell (1976).

Pesq. agropec. bras., Brasília, v.35, n.6, p.1143-1149, jun. 2000 
As populações CPA 5202 A, CE 1 e CMS 41, com menores produções, apresentaram resistência a uma deterioração da qualidade ambiental, ou seja, com pouca oscilação nos ambientes desfavoráveis $\left(\hat{b}_{1}<1\right)$; porém, apresentaram respostas proporcionais às mudanças de ambientes favoráveis $\left(\hat{\mathrm{b}}_{1}+\hat{\mathrm{b}}_{2}=1\right)$. A população CMS 41, a única de ciclo superprecoce, ou seja, com florescimento masculino médio inferior a 60 dias, foi o genótipo que apresentou a menor produção, ficando $27,13 \%$ abaixo da produtividade média dos ensaios. As estimativas obtidas para $\mathrm{R}^{2}$ foram, no tocante a esses quatro genótipos, inferiores a $80 \%$, o que indica instabilidade na previsibilidade de resposta.

\section{CONCLUSÕES}

1. Os genótipos diferem em adaptabilidade, sendo que os híbridos têm maior adaptação (produção acima da média) que as populações e cultivares; o C 901 apresenta-se com adaptabilidade ampla tendo o mesmo nível de resposta, tanto em ambientes favoráveis como desfavoráveis.

2. As populações com maiores adaptação e estabilidade de produção nos ambientes estudados são as CMS 54 e CMS 59 que diferem quanto a adaptação nos ambientes favoráveis; estas populações não diferem das populações CEP 304, OC 202, CMS 11 e Composto Jaíba que também são estáveis.

3. As populações com melhor adaptação apresentam $b_{1}>1$ indicando serem responsivas nos ambientes desfavoráveis.

4. As populações CMS 50 e BR 106 são as mais responsivas e mais adequadas para cultivos em ambientes favoráveis.

5. As populações com resistência à deterioração ambiental $\left(\mathrm{b}_{1}<1\right)$ apresentam baixa adaptação (produtividade abaixo da média) sendo a melhor a IACTaiúba.

\section{AGRADECIMENTOS}

Aos pesquisadores Paulo de J. Pereira, Pedro M. Araújo, Everton D. Souza, Marlene Lima, Eliezer Winkler, Luiz Torres, Lucia Valentini, Luiz C. Vieira, Cosme D. Cruz. Alvaro E. da Silva, Celso Aguiar, Carlos P. Leite e Luiz M. S. Aguiar, pela colaboração nas instalações para obtenção dos dados dos ensaios e fornecimento dos dados climatológicos.

\section{REFERÊNCIAS}

ARIAS, E.R.A. Adaptabilidade e estabilidade das cultivares de milho avaliadas no Estado do Mato Grosso do Sul e avanço genético obtido no período de 1986/87 a 1993/94. Lavras : UFLA, 1996. 110 p. Tese de Doutorado.

ARIAS, E.R.A.; RAMALHO, M.A.P.; FERREIRA, D.F. Adaptabilidade e estabilidade de cultivares de milho avaliadas no Estado de Mato Grosso do Sul. Ciência e Agrotecnologia, Lavras, v.20, n.4, p.415-420, out./dez. 1996

BECKER, H.C.; LEÓN, J. Stability analysis in plant breeding. Plant Breeding, Berlin, v.101, p.1-23, 1988

CROSSA, J. Statistical analysis of multilocations trials Advances in Agronomy, San Diego, v.44, p.55-85, 1990.

CRUZ, C.D.; TORRES, R. da A.; VENCOVSKY, R. An alternative approach to stability analysis proposed by Silva and Barreto. Revista Brasileira de Genética, Ribeirão Preto, v.12, n.3, p.567-580, 1989

EBERHART, S.A.; RUSSELL, W.A. Stability parameters for comparing varieties. Crop Science, Madison, v.6, n.1, p.36-40, Jan./Feb. 1966

FINLAY, K.W.; WILKINSON, G.N. The analysis of adaptation in plant breeding programme. Australian Journal of Agricultural Research, Melbourne, v.14, p.742-754, 1963.

HALLAUER, A.R. Development of single-cross hybrids from two eared populations. Crop Science, Madison, v.7, p.192-195, 1967.

HALLAUER, A.R.; MIRANDA FILHO, J.B Quantitative genetics in maize breeding. Ames Iowa State University Press, 1981. 486p.

KRUG, C.A.; VIEGAS, G.P.; PAOLIERI, A. Híbridos comerciais de milho. Bragantia, Campinas, v.3, p.367-552, 1943. 
LIN, C.S.; BINNS,M.R.; LEVKOVITCH, L.P. Stability analysis: where do we stand. Crop Science, Madison, v.26, n.5, p.894-900, 1986.

LIN, C.S.; BINNS, M.R. A superiority measure of cultivar performance for cultivar x location data Canadian Journal of Plant Science, Ottawa, v.68, n.1, p.193-198, 1988.

LONNQUIST, J.H. Mass selection for prolificacy in maize Der Züchter, Berlin, v.37, p.185-188, 1967.

NASPOLINI FILHO, V. Variabilidade fenotípica e estabilidade em híbridos simples, híbridos duplos, variedades e compostos de milho (Zea Mays $\mathbf{L}$.) Piracicaba : USP-ESALQ, 1975. 68p. Dissertação de Mestrado.

PATERNIANI, E.; MIRANDA FILHO, J.B. Melhoramento de população de milho. In: PATERNIANI, E.; VIEGAS, G.P. (Ed.). Melhoramento e produção de milho no Brasil. Campinas : Fundação Cargill, 1978. p.202-256.
PIMENTEL-GOMES, F. Curso de estatística experimental. 13.ed. Piracicaba : ESALQ, 1990. 468p.

PINTHUS, M.J. Estimate of genotypic value: a proposed method. Euphytica, Dordrecht, v.22, p.121-123, 1973

RUSSELL, W.C. Produção e estabilidade de comportamento de híbridos não prolíficos e prolíficos. São Paulo : Fundação Cargill, 1976. 39p.

SPRAGUE, G.F. Corn breeding. In: SPRAGUE, G.F. (Ed.) Corn and corn improvement. New York : Academic, 1955. p.221-292.

VENCOVSKY, R.; BARRIGA, P. Genética no fitomelhoramento. Ribeirão Preto : Sociedade Brasileira de Genética, 1992. 495p

VERMA, M.M.; CHAHAL, G.S.; MURTY, B.R. Limitations of conventional regression analysis: a proposed modification. Theoretical and Applied Genetics, Berlin, v.53, p.89-91, 1978 